\title{
A ARTE DA PERFORMANCE COMO AÇÃO CULTURAL EM ESCOLAS PÚBLICAS DE UMA PERIFERIA NA CIDADE DE SÃO PAULO Os sentidos da transgressão como componente dessa linguagem no Universo Escolar
}

\author{
EL ARTE DE LA PERFORMANCE COMO ACCIÓN CULTURAL EN \\ ESCUELAS PÚBLICAS DE UNA PERIFERÍA EN LA CIUDAD DE SÃO \\ PAULO
}

Los sentidos de la transgresión como componente de ese lenguaje en el Universo Escolar

\section{THE ART OF PERFORMANCE AS A CULTURAL ACTION IN PUBLIC SCHOOLS OF A PERIPHERY IN THE CITY OF SÃO PAULO \\ The senses of transgression as a component of that language in the School Universe}

\author{
Thiago Camacho Teixeira ${ }^{1}$
}

\begin{abstract}
RESUMO
Este artigo pretende trazer apontamentos teóricos, metodológicos e práticos sobre as construções cênicas e próprias da linguagem da performance, elaboradas por meio de experiências estético sensoriais, seus decorrentes relatos e repercussões no interior das escolas públicas, localizadas no interior de uma perifeira da Zona Sul da cidade de São Paulo, tendo em vista o diálogo entre artistas - inclusive em formação, professores, estudantes, comunidades escolar e local. Também tem o intuito de discutir os sentidos da transgressão, componente próprio da linguagem, no ambiente escolar.

PALAVRAS-CHAVE: arte como experiência, arte-educação, liberdade de expressão
\end{abstract}

\section{RESUMEN}

Este artículo pretende traer apuntes teóricos, metodológicos y prácticos acerca de las construcciones escénicas y propias del lenguaje de la performance, elaboradas por

\footnotetext{
${ }_{1}^{1}$ Mestrando no Programa de Pós-graduação da Escola de Comunicações e Artes - ECA da Universidade de São Paulo - USP. 2017. Graduado pelo curso de Arte-Teatro da Universidade Estadual Paulista. (UNESP). Cursou o primeiro semestre do curso de Graduação em Artes Cênicas da Universidade Federal de Ouro Preto (UFOP) - (2012), onde foi aprovado em terceiro lugar em ampla concorrência. Possui graduação em Letras - Português, Inglês e Literatura pela Universidade Paulista (2009). Ator com DRT, Performer e Professor de artes, teatro, literaturas e línguas. Desenvolve um trabalho pessoal e independente de pesquisa com registros e produções da Performance, entre os quais estão vídeos e fotografias. Professor de Línguas Portuguesa e Inglesa e de Literaturas no Ensino Fundamental II e Médio das redes municipal e estadual de São Paulo desde 2010. Membro participante do grupo de teatro e performance Desvio Coletivo. Foi membro do grupo Teatro Didático e da rede de pesquisadores do Portal Teatro Sem Cortinas, ambos projetos de extensão da UNESP. Iniciou sua produção dramatúrgica com a Comédia A Gaivota.
} 
medio de experiencias estético sensoriales y por medio de sus derivados relatos y repercusiones en el interior de las escuelas públicas, localizadas en el interior de una perifea En la zona sur de la ciudad de São Paulo, teniendo en vista el diálogo entre artistas - incluso en formación -, profesores, estudiantes, comunidades escolar y local, y sociedad. También ha comprendido la intención de discutir los sentidos de la transgresión, componente propio del lenguaje, en el ambiente escolar.

PALABRAS CLAVE: arte como experiencia, arte-educación, libertad de expresión

\begin{abstract}
This article intends to bring theoretical, methodological and practical notes about the scenic and proper constructions of performance language, elaborated through aesthetic sensorial experiences and through its consequent reports and repercussions within the public schools located inside a periferics neighboardhood in a South zone of the city of São Paulo, in view of the dialogue between artists - including in formation -, teachers, students, school and local communities, and the society. It has also understood the intention of discussing the meanings of transgression, a specific component of language, in the school environment.
\end{abstract}

KEYWORDS: art as experience, art-education, freedom of expression

\title{
1. A EXPERIÊNCIA COMO INVESTIGAÇÃO - POR QUE A EXPERIÊNCIA É PESQUISA?
}

\subsection{Considerações sobre a pesquisa qualitativa em artes cênicas}

A amplitude do tema desta pesquisa quando se refere à performance enquanto ação cultural, ou mesmo quando a localiza no ambiente escolar público, é logo justificada quando a relacionamos aos seus aspectos e indicações qualitativos, tais como: é preciso que o espaço de criação em respaldo à perspectiva subjetiva seja amplo e livre, para que a partir desses quesitos provenientes do conceito de liberdade, no seu sentido quase anárquico ou anarcoartístico sejam postos os limites de cada um, de cada agente, de cada artista - ou não-artista, na busca da apropriação de uma linguagem que não tem muita afinidade com a restrição, e que parte da experiência e da produção que emana do Ser (HOLLIDAY, 2006).

No aspecto da qualidade e do processo, mais do que frente aos eventuais resultados, ou demonstrações quantitativas, em performances, a investigação está centrada na arte como experiência, antes mesmo de suas especificidades virem à tona. É por isso que não me intimidei em não recortar mais o grande tema, dentro do qual as possibilidades de criar deveriam a meu ver estar de fato ampliadas. Cada processo e 
cada ação não deveriam encontrar quaisquer barreiras, e nenhum tipo de impedimento para a livre fruição, para o encontro e desencontro, conhecimento e desconhecimento em um campo expandido. A intimidade geral dos sujeitos em processo de criação com o que a linguagem contém de específica deveria vir com as práticas, com o conhecimento autônomo, embora mediado por uma orientação do propositor e por referências autorais importantes - ainda que estas mesmas autoridades também incentivassem as constantes rupturas. Em performance como uma linguagem transgressora, há que se subverter seus próprios sistemas, e essa transformação contínua é uma de suas grandes marcas, sem as quais estaríamos negligenciando um caráter próprio dessas manifestações.

O que temos de especificidade em um tema como performance na escola, está passível de desconstrução e de se tornar inespecífico a todo instante, pois é aquilo que vira alvo comum a ser problematizado. Uma forma de expressão subversiva está quase que permanentemente desestabilizando lugares estáveis e, portanto, delimitar não é uma escolha pertinente quando se pensa em gênese de uma pesquisa nesse território.

Diante de um universo propositalmente instável e consolidado naquilo que tangencia as definições imutáveis, temos uma metodologia, que une ação cultural, criação coletiva e presentificação, isto é, repertórios de conceitos, com percepções do mundo e do espaço escolar a partir de experiências subjetivas e também da cultura (PEREIRA, 2013, 2015). Cada ação a versar sobre a percepção dos envolvidos acerca de suas próprias realidades, poetizadas, idealizadas, superestimadas ou não, no intuito de transformar, ressignificar, construir e reconstruir a partir do olhar sensível, íntimo, e também engajado. Com objetivos ligados a suscitação do movimento do pensamento e do fazer artístico, as tendências a contestar a própria noção de arte na contemporaneidade, e desterritorializar lugares comuns e enrijecidos do saber, um saber muitas vezes fora de contexto, que não só não funciona, mas opera com aspereza no desenvolvimento cognitivo e mais tarde no desenvolvimento social.

$\mathrm{Na}$ pesquisa qualitativa em artes cênicas, e como dito em performance, temos um campo de ações experimentais, que valem muito por seus processos, e é nessa direção que este presente texto tenta ir no propósito de descrever tais caminhos e práticas e assim refletir criticamente. 
A partir de reflexões em torno do conceito de pesquisa qualitativa e de seus princípios, ficam evidentes para mim, frente as minhas práticas como artista-educador e pesquisador, as considerações de que: A experiência pode aparecer enquanto forma própria de investigação. Com essa constatação a que Oscar Jara Holliday (2006) me ajudou a atingir ainda vem à tona a compreensão de que cada indivíduo tem a sua experiência e seu campo sensorial próprio, o que significa dizer que além de ser influenciado pelo meio, por sua trajetória de vida, pela tessitura sócio-cultural e política de que é proveniente, é também produtor de sua própria imanência subjetiva e ontológica. Esse grupo de influências sobre seu próprio modo de produção, de investigar e de saber conhecer, e as premissas de que cada Ser social é um universo, consubstanciam a possibilidade de sistematizar vivências no interior de suas próprias lógicas.

A afirmação de que cada investigador pode encontrar a sua própria identidade na pesquisa também pressupõe sua natural e corrente marca: a contradição. $O$ interesse em buscar a compreensão justamente daquilo que não é um 'ponto pacífico', isto é, que está passível de questionamentos e superações, permite-nos lembrar que a essência da busca é partir do que já sabemos para obtermos algo a mais, e que o conhecimento anterior é uma ponte essencial para tanto. Nessa perspectiva, conhecer com vistas voltadas à marca da qualidade, mais do que a quantidade, mais ao processo do que aos eventuais resultados, é assumir o diálogo e a contradição. Viver e transformar essas vivências em sistemas, sejam eles induzidos ou espontâneos, demanda a sensibilidade de perceber o outro como portador de voz e como capaz de troca. A experiência na pesquisa se estabelece com o outro, inclusive quando é autobiográfica, porque a nossa própria história acontece sob o crivo dessas relações. E, assim sendo, o autor citado nos abre a visão para mais um entendimento: para esse tipo específico de busca, o sustentáculo epistemológico é a concepção metodológica dialética. Esta, por sua vez, "entende que a realidade histórico-social como uma totalidade, como processo histórico: a realidade é, ao mesmo tempo, una, mutante e contraditória porque é histórica; porque é produto da atividade transformadora, criadora dos seres humanos" (HOLLIDAY, 2006, p.6). 


\subsection{0 aprendizado da comunidade por meio da experiência}

Compreender a realidade social composta por espaços partilhados e ao mesmo tempo por espaços de disputa, sabendo-se que o processo histórico é o da legitimidade do conflito, permite que na perspectiva da pesquisa qualitativa tenhamos a percepção expandida do campus, do conhecimento, do nosso próprio olhar crítico e do objeto. Permite vermos o processo histórico como luta de classes, o que torna o trabalhador consciente de sua posição na sociedade, permite que entendamos a própria educação como um mundo de concepções e ideias plurais, muitas vezes divergentes, permite percebermos o currículo escolar como um espaço de disputa de conteúdos, e permite que vejamos a experiência como um acontecimento da diversidade.

Sistematizar conhecimentos e percepções da cultura pressupõe um movimento espiralar de construção e reconstrução dos saberes a partir de contradições, problematizações e descobertas. Holliday (2006) nos demonstra que algumas barreiras nos impedem de sistematizar, entre elas a ideia de que isso é complicado, especializado ou enfadonho. Por parecer pouco claro de que forma e quem deve sistematizar. Pela falta de programação de momentos voltados a sistematização, o que revela, segundo o autor carências sobre a reflexão institucional acerca de nosso trabalho e que não se dá prioridade a essa tarefa, colocando em distância diretores e educadores-animadores e a deixar claro as diferenças entre avaliar, sistematizar e a pesquisa. A deixar claro também a oposição e reação a formalidade positivista, enquanto que o aspecto qualitativo evoca concepções epistemológicas dialéticas.

$$
* * *
$$




\subsection{A busca por uma linguagem plural, multifacetada, e que se ligue a experiência da ação social}

Outros aspectos reflexivos acerca da sistematização surgem no texto, e nos chama a atenção, tais como: A escolha do que sistematizar como elemento central, ou completo, ou parte do objeto concreto, e a finalidade, isto é, pensar nos objetivos gerais e específicos: se é para engrandecer a prática, se é para entendê-la, para a partilha de experiências e etc.

E uma das mais relevantes considerações: a coerência do processo metodológico e de sua escolha frente à proposta teórico-filosófica contextual da própria pesquisa. $\mathrm{O}$ autor reitera que as diferenças de método tem a ver com tudo isso: objetivos, contexto, experiências com características particulares, objetos, e práticas de quem formula a proposta.

(...) as condições do contexto em que se desenvolvem; situações particulares a enfrentar-se; ações dirigidas para se conseguir determinado fim; percepções, interpretações e intenções dos diferentes sujeitos que intervêm no processo; resultados esperados e inesperados que vão surgindo; relações e reações entre os participantes (HOLLIDAY, 2006, p 21).

É neste sentido que quero falar um pouco de como a minha experiência, dentro do campo popular, da educação pública, da promoção social atravessada pelos conflitos da realidade cultural que me circundam, segundo a minha própria percepção, criando o mundo e sendo criado por ele, foi sendo organizada, reconstruída, e disseminada, enquanto sistematização.

(...) As práticas de educação popular buscam inserir-se nos processos sociais e organizativos da população, visando à resolução de seus problemas, necessidades e aspirações, num contexto bem determinado. Em qualquer caso, põem-se em marcha ou impulsionam- se processos sociais de ação consciente e organizada, por meio de uma reflexão crítica de sua situação, que permitam modificá-la no sentido do projeto histórico popular. Ele conduz, normalmente, à elaboração de estratégias político-pedagógicas de intervenção, em função do apoio e potencialização do protagonismo de distintos sujeitos populares. Estamos, então, diante de experiências da realidade que são susceptíveis de ser entendidas e, portanto, sistematizadas de maneira dialética. Essas experiências de educação popular ou de promoção em geral, podem ser lidas ou compreendidas como uma unidade rica e contraditória, cheia de elementos constitutivos que estão presentes num movimento próprio e constante. Além disso, estas experiências, estes processos sociais, organizativos e culturais muito específicos, estão, por sua vez, relacionados com outros processos da realidade que possuem características similares. Este ponto de partida é o que nos permite aproximar-nos da sistematização a partir do que a própria riqueza das experiências pede que se faça: apropriar-se da experiência vivida e dar conta dela, compartilhando com os outros o aprendido. (HOLLIDAY, 2006, p. 21) 
Entender a experiência como investigação pode ser como em um paralelismo entender a vida como a própria arte. Isto é, podemos falar em superação das barreiras entre pesquisa e vivência, assim como podemos falar em superação das barreiras entre arte e vida.

\section{A PERFORMANCE COMO LINGUAGEM, A CONTEMPORANEIDADE E A AÇÃO CULTURAL}

\subsection{Renato Cohen, Marvin Carlson, Schechner e performance como termo contestado}

A performance, os seus estudos e modos de produção relacionados a vida, a sociedade, e a política, elencadas a hibridez e a transversalidade de campos do conhecimento, ampliam seus domínios de influência após os anos 60 e 70 . Buscar estas referências históricas do termo e depois da linguagem no trato que damos a ação cultural na escola pública é fundamental para entendermos a prática expressiva neste terreno historicizado.

Em texto de minha autoria, traço um caminho da performance que mais nos interessa para recorrer a ela como ação cultural em espaços públicos e escolares. Transcrevo em citações trechos essenciais com algumas alterações e intervenções (TEIXEIRA, 2016).

Performance, para Marvin Carlson (1980), é um termo de historicidade. Em determinados períodos tem significação e sentido híbrido e de fronteira entre campos semânticos.

Carlson (1980) segundo sua pesquisa sobre o termo diz que performance pode, ao longo do tempo significar as seguintes distinções que não se definem como mais ou menos próprias, e as quais mais nos interessam:

a- A desenvoltura de alguma ação, e a demonstração de habilidade de algum fazer. Como um concerto de piano ou um festival de dança ou circo, dentro dos quais o pianista, o bailarino, e o palhaço exibem seus talentos e as nuances de suas atividades artísticas. 
b- A desenvoltura e a eficácia de ações a partir de objetos e coisas, isto é, de atributos vinculados ao não-humano, como o tempo entre o início e o fim de uma mistura química em que os elementos realizam uma 'performance' até o resultado final da experiência.

c- Em um conceito de Richard Bauman, pode significar o esforço que fazemos para representarmos socialmente os papéis que, codificados por normas da cultura e esperados pelas tradições e costumes, executamos em nosso dia-a-dia, a exemplo das diferenças de comportamento que assumimos em nossa residência ou na empresa ou instituição onde trabalhamos frente aos nossos superiores e chefes.

d- A performance com sentido Estético e de atividade de um atuante emissor, na perspectiva artística, começa a ganhar sentido para Carlson (1980) a partir de Bauman, quando ele nota que o filósofo identifica uma duplicidade ou multiplicidade na consciência, e uma intencionalidade, na representação dessas identidades sociais, quando finalísticamente orientadas para a expressão subjetiva ligada à arte. Então, como termo de nossa pesquisa, aparece-nos a performance-arte. (CARLSON, 1980, p. 11-20).

Ainda diante da introdução crítica a performance de Carlson (1980), ele nos mostra os estudos de Richard Schechner ao estabelecer sete "áreas em que a teoria da performance e as ciências sociais coincidem" (CARLSON, 1980, p. 22).

1. Performance na vida diária, incluindo reuniões de qualquer tipo.

2. Estrutura de esportes, rituais, jogos e comportamentos políticos públicos.

3. Análise de vários modos de comunicação (diferentes da palavra escrita) semiótica.

4. Conexões entre modelos de comportamento humano e animal com ênfase no jogo e no comportamento ritualizado.

5. Aspectos da psicoterapia que enfatizam a interação de pessoa para pessoa, a encenação e a consciência do corpo.

6. Etnografia e pré-história - tanto das culturas exóticas quanto das familiares.

7. Constituição de teorias unificadas de performance, que são na verdade, teorias de comportamento.

A lista de Richard Schechner é, de algum modo, reminiscente de uma tentativa semelhante de sugerir futuras áreas de pesquisa entre o teatro e as ciências sociais, publicada em 1956 por George Gurvitch, para resumir os trabalhos de uma conferência francesa sobre o assunto. Antecipando o estudo subsequente de pesquisadores como Goffman e Turner, Gurvitch chamou a atenção para os elementos teatrais ou de performance em todas cerimônias sociais, mesmo numa 'simples recepção ou reunião de amigos' (CARLSON, 1980, p. 22-23). 
Estes conceitos da performance como um termo contestado são para Carlson (1980) dispositivos que nos fazem compreender melhor a sua evolução temporal, até que os seus sentidos como ação artística se engendrem.

Performar, segundo Cohen (2007), corresponde a um ato de emissão subjetiva, da expressão cênica, inserindo-se, desse modo, nas artes da representação ou da presentificação - termo debatido - do atuante em cena. Enquanto fenômeno semiológico se consubstancia no tempo e no espaço em ação e- ou de um possível eulírico para o outro, com a reportagem ou a permissão relacional, dialógica da informação ou expressividade e, às vezes, da e na inversão atuante-público. A performance pode ocorrer em diversas localizações, desde as praias, piscinas, elevadores, e museus, às igrejas, praças, ruas, edifícios, palcos, e especialmente, nas escolas e ambientes de educação. A amplitude temporal desta ação é muito variável e flexível e pode se estender de minutos a dias ou mais.

$\mathrm{O}$ ato de performar como ato intencional e ligado à expressão artística deve suas origens às Artes Visuais, tornando-se um meio híbrido da expressão e das dimensões dinâmico-espaciais. Em uma noção estendida da performance, o (a) atuante pode ser um artista ou um não-artista; embora os mesmos possam se retirar de cena ao deixarem em seus lugares um boneco, um animal, um objeto instalado ou formas abstratas e concretas quaisquer. O texto pode ser simbólico, o que se pode entender pela representação em código compartilhado verbal ou não-verbal, imagético-icônico, e -ou mesmo indicial, em relação de causa e consequência, e dessa forma, a ação é constituída por amplo campo de possibilidades semiológicas.

\subsection{Quem sou eu?}

Esta pergunta orienta o modo da pesquisa, seus objetivos, como estes são perseguidos, os motivos que me levaram a escolher o objeto, o tema, a indução de resultados e produção de campo, entre outros aspectos essenciais da investigação da experiência.

E respondendo a essa pergunta, eu poderia dizer que sou um performer, e agora pesquisador da arte da performance. E falar muito disso. Poderia dizer também 
que sou performer desde que comecei a produzir para teatro e descobri que minha atuação se circunscrevia mais a linguagem da vivência, do sensorial a flor da pele, da idiossincrasia, da abstração conceitual, da minha intensa subjetividade, das colagens, e da minha utopia pessoal, isto é, da performatividade muito mais que da representação teatral das personagens. Mas essa descoberta levou bastante tempo, e essa história seria muito longa já que me empolgo muito com essa 'coisa' autobiográfica. Na realidade, eu descobri que era performer quando já o era há muito mais tempo. A performance e a sua conceituação remontam a minha infância quando eu ia a escola como se estivesse indo a um show. Então quando voltei à escola como professor, quis voltar como um professor- performer, do mesmo modo que há muitos anos atrás. Como se fosse um show. Prefiro, neste caso, contar de modo subjetivo, experimental, e não obstante, qualitativo, um pouco na minha pesquisa nesse locus como um recorte de todo esse percurso - o campo: escola, e por meio do citado instrumental, a performance como linguagem, falar acerca de minhas atividades pedagógicas na arte-educação.

A educação artística e a arte em si têm relações essenciais como forma de atingir a transcendência, de ultrapassar a pasmaceira da vida comum do dia-a-dia, na nossa sociedade hiper-racionalizada, e busca no âmago do sentir as formações que dele decorrem.

Em 2014, enquanto professor da Educação Básica no Ensino Fundamental II e Médio, na Escola Estadual Professor Renato Braga, em uma periferia da Zona Sul da cidade de São Paulo, iniciei minhas experimentações na escola em todas essas séries, desde o sexto ano até a terceira série final do Ensino Médio, com foco central nesta última, por meio de ações que aos poucos se revelaram performativas. Tanto pelo caráter de eventualidade dos feitos e pela subjetividade expressiva que podia se notar nos estudantes, quanto pela natureza política do que estava sendo produzido e pelo que entendíamos acerca do meio de expressão identificado: um canal de reivindicação e uma forma de manifestação. Naquele momento, a criação em conjunto nos tempos e espaços propostos tiveram como disparadores os anseios e expectativas estudantis relacionados tanto as realidades locais e pessoais dos jovens em questão, em relação à escola, aos professores, a comunidade e mais amplamente a sociedade, quanto aos 
momentos políticos atrelados de grande repercussão midiática e cultural. O período era pós- manifestações de 2013 no Brasil, insurgência do MPL - Movimento PasseLivre, que protestava contra o aumento da passagem dos transportes públicos em São Paulo, ações repreendidas drasticamente pela força de Estado da PM - a Polícia Militar, evento notório e a partir dele considera-se a eclosão em grandes atos por todo o país. Sentindo- se mobilizados, os estudantes sugeriram em conversas e debates informais em sala de aula sobre a possibilidade de se manifestarem politicamente a versar sobre a justiça social. E sobre como isso podia partir de atividades fomentadas na e pela própria escola. A reflexão também se deu porque os indivíduos do grupo identificavam problemas com a educação pública a nível nacional, e especialmente Estadual, em São Paulo - referente às suas próprias inserções históricas e reais. Todos sabem que muitas escolas ainda hoje, em 2017, se encontram em condições de péssima infraestrutura, falta de água, recentemente de merenda, sobre a desvalorização dos professores da rede pública, etc. - e aqueles estudantes em 2013 percebiam a importância da liberdade de expressão e o quanto as linguagens e as artes poderiam lhes servir de instrumento para projetar suas vozes plurais, dúvidas e anseios, em busca de suprir necessidades públicas, subjetivas, e tendo em vista a ampliação e criação do que já entendiam por direitos e deveres na política e pelo que já pressupunham por espaço privado e espaço público. Nesse momento, procurei pensar em como poderia atender as demandas que se apresentavam de modo que estes estudantes pudessem ter algumas experiências com a comunicação e expressão por meio da linguagem não-verbal, também pertencente ao plano estadual de ensino, currículo e programa de educação do Estado de São Paulo para as disciplinas, as quais eu lecionava: Línguas Portuguesa, Inglesa, e Literaturas, e de modo que pudessem ter contato com a modalidade de estudo a qual já era meu objeto de observação: a arte da performance como linguagem e as suas possibilidades sensoriais e semiológicas marcantes e diversas.

Houve debate e nele discutimos durante algumas aulas sobre o que queríamos falar, sobre o momento delicado vivido e como construiríamos esses discursos de modo que todos fossem representados, a princípio, por questões inerentes ao grupo como um todo, a partir da escola e das questões sociais e políticas em voga. Decidimos então que 
falaríamos sobre a necessidade de expor um aspecto que os estudantes sentem como comum em suas vivências e em seus contextos específicos: a alienação. Ligados ao senso comum e levando em consideração a experiência concreta dos sujeitos, naquele momento entendíamos por alienação a forma anestesiante e dissimulada das instâncias políticas governamentais tratarem a população, no paralelo: negligência do Estado com as necessidades fundamentais, entre as quais, a educação pública gratuita e de qualidade. Neste intento, pensamos em quais materiais poderíamos utilizar e de que formas poderíamos representar a alienação, isto é, o enrijecimento do pensamento crítico e a ideia anestesiante e sustentada pelo conformismo dos corpos dóceis (FOUCAULT, 1975) mencionada anteriormente.

Elegi, a partir de uma inspiração de um dos grupos de Teatro Visual dos quais eu era integrante, a máscara neutra (COPEAU, 1929) como recurso, e essa atividade consistia a princípio em: os estudantes cobrirem seus rostos com um pano branco, especificamente fraldas de pano.

A máscara neutra foi uma forma de metodologia utilizada por Jacques Copeau (1929) para corrigir vícios de movimentação dos atores e transformar o teatro vigente que, segundo ele, "estava impregnado pelo exibicionismo dos atores, monstros sagrados, e pelos vícios interpretativos de um teatro de mãos e rosto" (SACHS apud COPEAU, 1929, p. 38), em busca de uma arte do espetáculo que saísse de seu instante meramente festivo e glamouroso para uma prática cênica de maior relevância técnica e também moral e ética. Para ele, este recurso potencializaria a precisão técnica do corpo e do movimento, ante o bloqueio dos vícios de expressão do rosto, ante o bloqueio parcial da visão e das iniciativas sem compromisso com o rigor da atuação.

Não se trata aqui de utilizar esse material somente para neutralizar a expressão desses estudantes em uma analogia entre alienação e expressão neutra, anestesiada e inerte, mas também de propiciar um estímulo sensorial do contato do material com o rosto, com a sensação de ver difusamente, de forma nebulosa, com a sensação claustrofóbica e sufocante que talvez, apenas talvez, tivesse relação com a realidade vivenciada: uma política de corrupção, exploração, negligência e de sufocamento da expressão pela repressão de Estado, e pela dissimulação dos valores na relação de direito público e ocultamento do descaso, em um cenário de reivindicação 
e de luta pela ampliação de direitos, característica que marca a democracia e o exercício da cidadania.

Após diversas ações expressivas de ocupação dos espaços no interior da escola com esse material, a máscara neutra, em ato performativo no intuito de representar, comunicar e expressar as sensações e vivências relatadas, frente ao objetivo de ampliar esses discursos poéticos e políticos construídos, envolvendo a comunidade e mais amplamente a sociedade, e utilizando ao mesmo tempo as ferramentas tecnológicas de nosso tempo, criei junto aos estudantes uma página no Facebook -a rede social com a qual eles tinham maior proximidade e experiência de uso- dentro da qual publicávamos nossos atos. O nome da página é A Escola Pública é Nossa, e está disponível no Facebook.

Segue abaixo uma das postagens que reporta uma das primeiras ações feitas por aqueles estudantes naquele ano:

No dia 31 de março de 2014, o Professor Thiago Camacho e seus alunos da Escola Estadual entraram em ação com a performance Indisciplinados, manifesto que teve intuito crítico com relação a negligência do Estado acerca da educação, do Sistema Público de ensino, da pouca valorização de professores e estudantes, estes últimos, filhos de trabalhadores. 


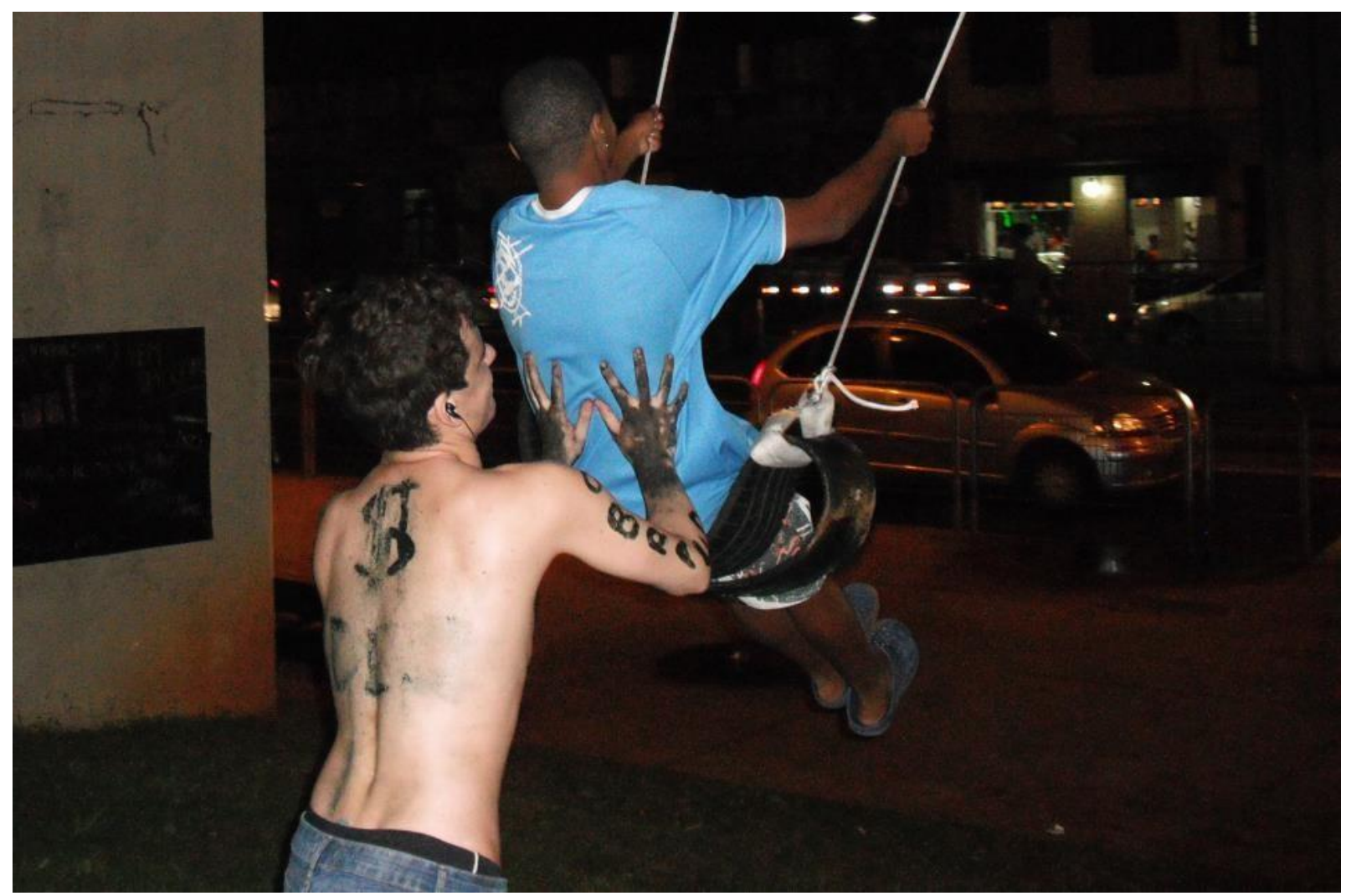

Gênese da ação A Escola pública é Nossa. Na foto: Thiago Camacho e um jovem integrante da ação. Escola Estadual Professor Renato Braga, São Paulo/ SP, 2013. Foto: Emerson Lisboa.

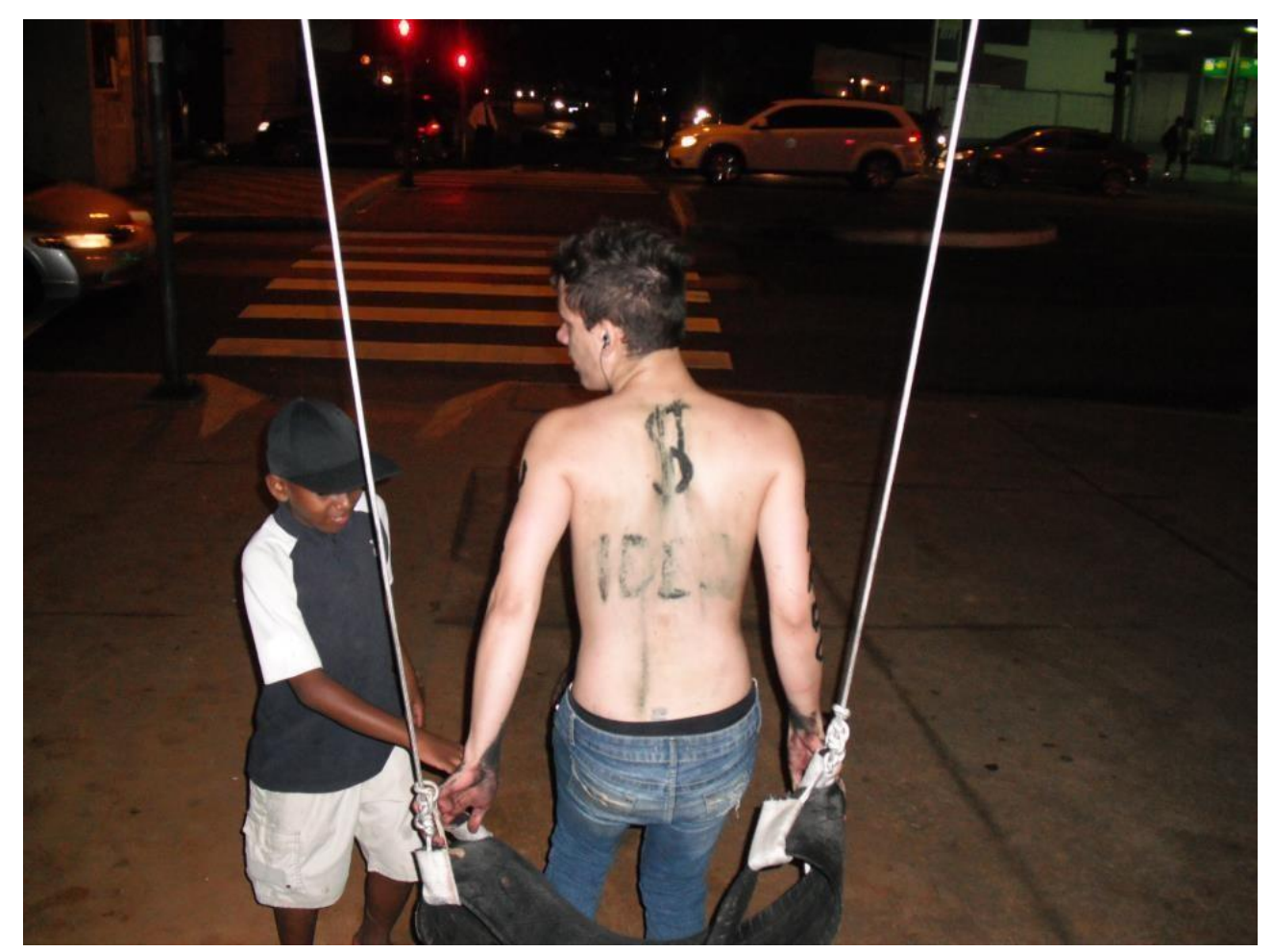

Gênese da ação A Escola pública é Nossa. Na foto: Thiago Camacho e um jovem integrante da ação. Escola Estadual Professor Renato Braga, São Paulo/ SP, 2013. Foto: Emerson Lisboa. 


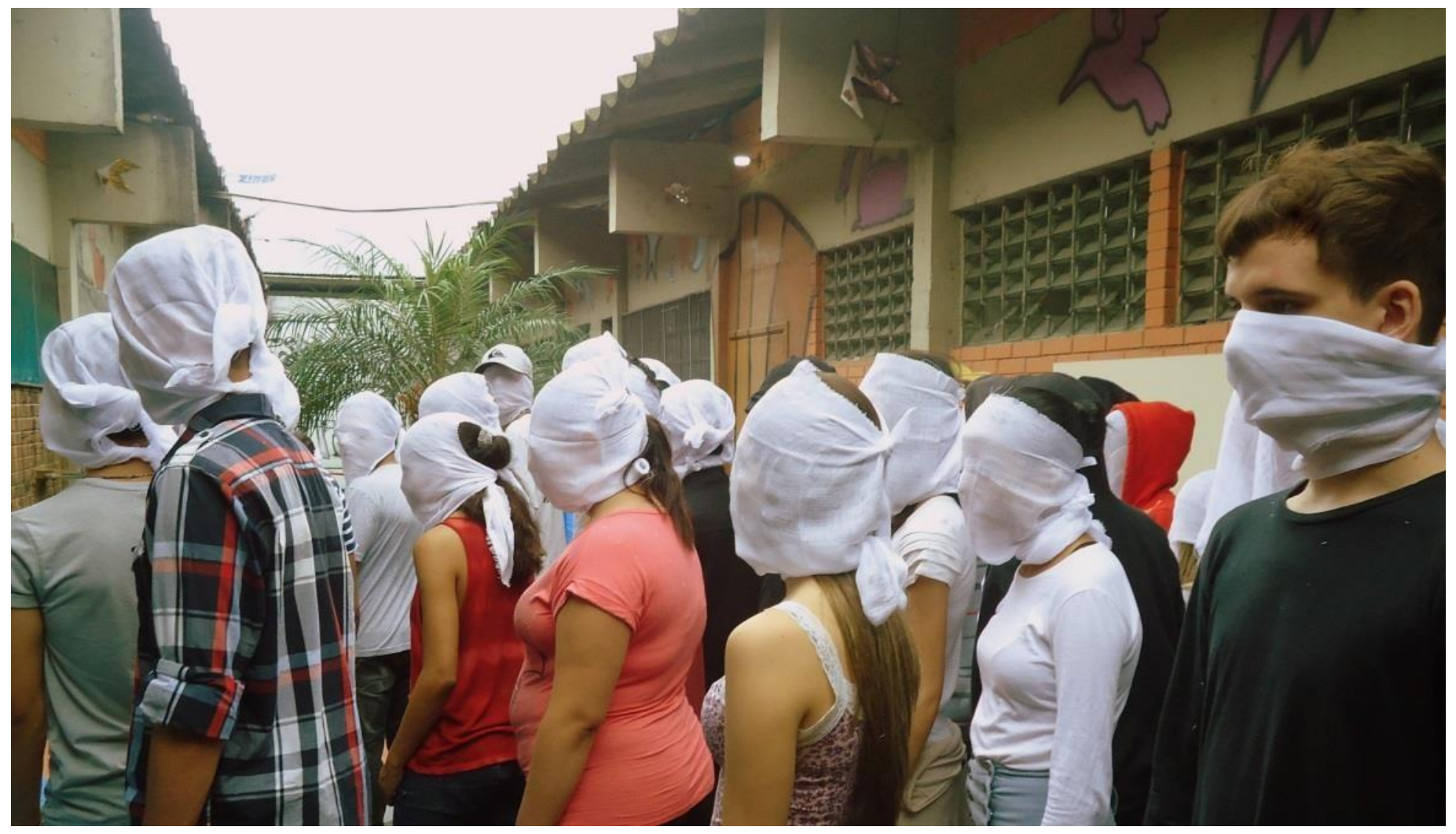

A Escola pública é Nossa. Escola Estadual Professor Renato Braga. São Paulo/ SP, 2014. Foto: Jared Mehmetof. 


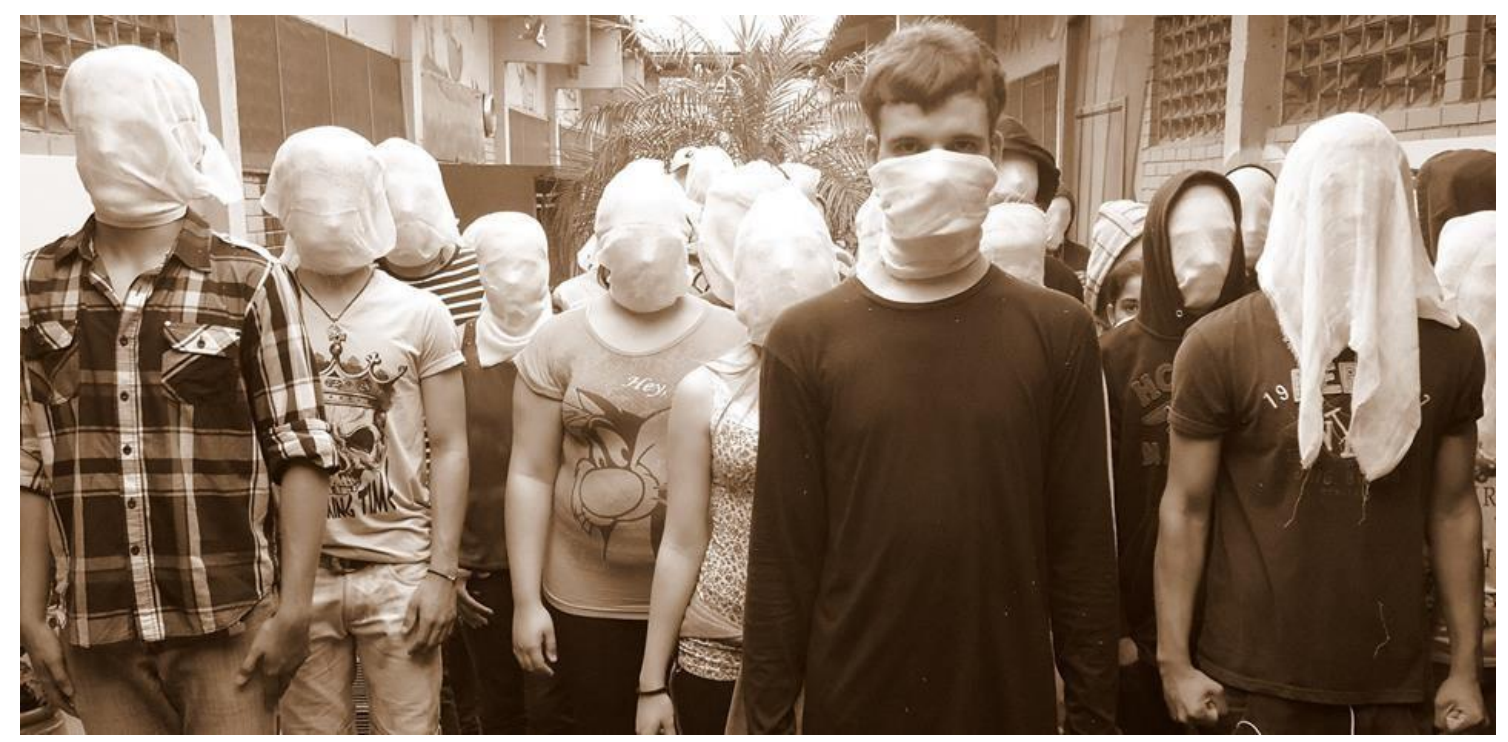

A Escola pública é Nossa. Escola Estadual Professor Renato Braga. São Paulo/ SP, 2014. Foto: Jared Mehmetof.

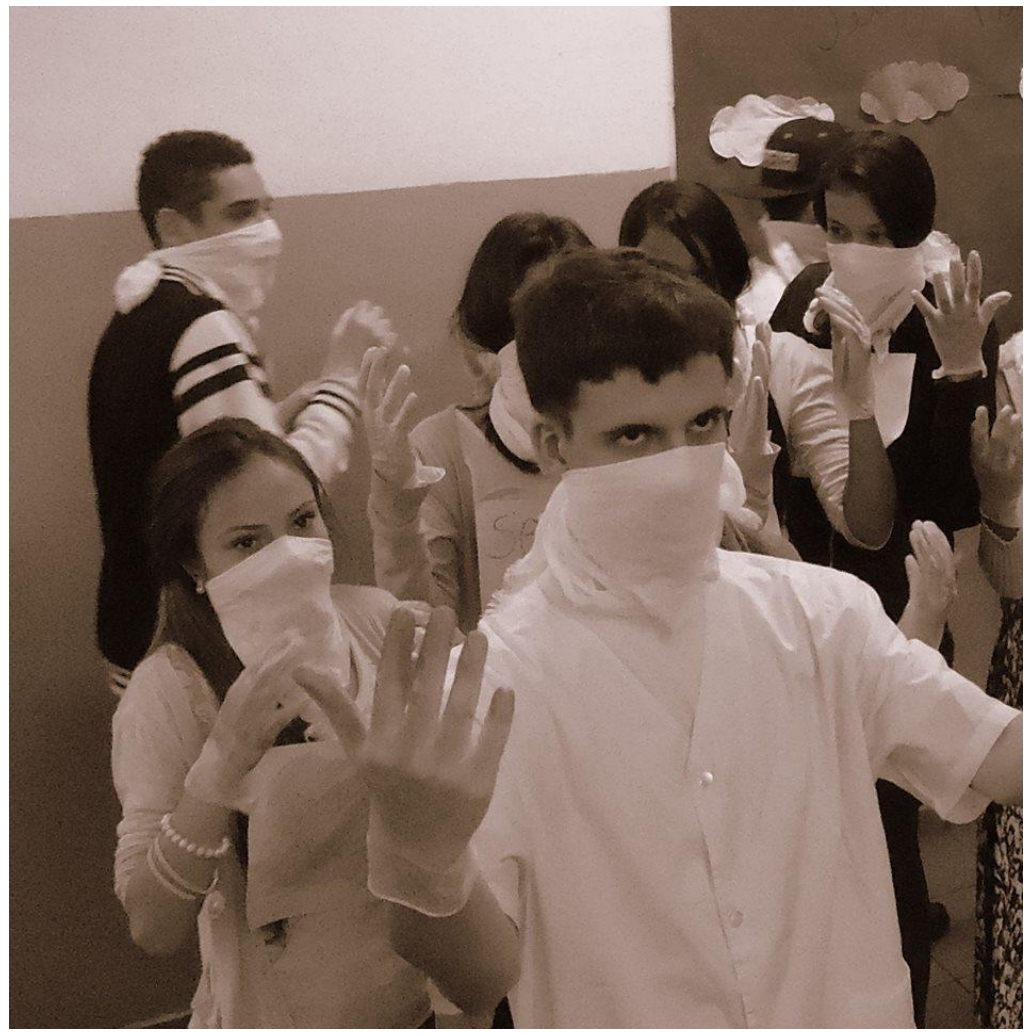

A Escola pública é Nossa. Escola Estadual Professor Renato Braga. São Paulo/ SP, 2014. Foto: Jared Mehmetof. 
Junto às postagens, haviam reflexões e ações, então pensamentos acerca da política, da Instituição Pública e da Filosofia política, com citações e referências relacionadas, que de modo algum representam uma opinião definida, impositiva ou fechada ao diálogo.

Houve e está ainda ocorrendo uma intensa atividade política durante os anos 2013-2018, frente à áspera crise econômica, a intensificação das reivindicações e manifestações contra e pró-governo, acerca do impeachment, encarado por parte da população como um golpe parlamentar, e fundamentalmente com as Ocupações das escolas estaduais pelos secundaristas em protestos contra a gestão Alckmin, g e s tão de 2011 a 2018, diante de suas reivindicatórias acerca da reorganização escolar da rede estadual de São Paulo, que fecharia escolas, e com a qual estes estudantes e parte dos professores discordavam. A base referencial que selecionei para reavaliar as ações performáticas com os estudantes depois dessa intensa atividade está ancorada em um pensamento ao qual me identifiquei e que representa os ensejos inclusive anteriores, quando já ocupávamos a escola com reivindicações e ações expressivas. Em entrevista para a Revista Cult, a filósofa e professora aposentada do curso de Filosofia da USP Marilena Chauí fez um pronunciamento que pode resumir a partir da visão política e filosófica como eu pensava a questão e o nosso projeto até então.

(...) a maior diferença entre a ocupação das escolas e o movimento de 2013 é que a paralisação aconteceu no interior de uma instituição pública e social para a garantia do caráter público dessa instituição. Não foi um evento em favor disso ou daquilo; foi uma ação coletiva de afirmação de princípios políticos e sociais. Os dois grandes princípios foram, primeiro, o princípio republicano da educação - a educação é pública; segundo, o princípio democrático da educação - a educação é um direito. A ação dos estudantes e professores foi tão significativa porque eles disseram: 'O espaço da escola é nosso. Somos nós, alunos e professores, que somos a escola'. Então, foi a 'integração de posse' das escolas pelos alunos e professores. É gigantesco o fato de alguém no Brasil pensar que algo público é nosso! (CHAUÍ, 2015).

Vale salientar que o trabalho escolar desencadeado pelos estudantes e por mim, como narrativas e reivindicações deles mesmos, dentre a divulgação das ações pela página criada e referida por nós - A Escola Pública é Nossa, todos eles possuem intuitos democráticos de apreço pelo pluralismo das concepções, e pela diversidade do pensamento, o que significa uma mudança de paradigmas na forma como entendo a justiça social hoje, enquanto educador, questionando também as disparidades das ideias radicais e extremistas das ideologias. 


\section{REFERÊNCIAS}

CARLSON, Marvin A. Performance: Uma introdução crítica. Belo Horizonte: Editora UFMG, 2009.

CHAUÍ, Marilena. Sociedade brasileira: violência e autoritarismo por todos os lados. Revista Cult, número e edição209, fevereiro 2016. Disponível em: $\quad<$ http://revistacult.uol.com.br/home/2016/02/sociedade-brasileira-violencia-eautoritarismo-por-todos-os-lados/\#respond >. Acesso em: 20 jul. 2017.

COHEN, Renato. Performance como Linguagem. São Paulo: Perspectiva, 2007. COPEAU, J. Reflexiones de um Comediante sobre "La paradoja", de Diderot. Buenos Aires: Editorial La Plêyade., 1929.

FOUCAULT, Michel. Corpos dóceis em Vigiar e Punir. Petrópolis: Vozes, 1975. HOLLIDAY, Oscar Jara. Para sistematizar experiências. 2006, Disponível em <http://www.mma.gov.br/estruturas/168/_publicacao/168_publicacao30012009115508. pdf $>$. Acesso em: 5 abr. 2018.

PEREIRA, Elvina Maria Caetano. Tv UFOP - Com Ciência - canal 31, episódio 12, apresentado pelo professor Antônio Marcelo Jackson. Publicado no You Tube em 22 fev. 2013. Disponível em: < https://youtu.be/1UtOFEcu_Gw>. Acesso em: 30 mar. 2018. PEREIRA, Elvina Maria Caetano. CulturAll, TV Horizonte, apresentado e produzido por João Eugênio. Data de exibição: 07 mai. 2015. Disponível em: $<$ https://www.youtube.com/watch?v=RS3D1sFKXSQ> . Acesso em: 8 mai. 2017. TEIXEIRA, Thiago Camacho. A arte da performance como proposta pedagógica de comunicação e expressão no Ensino Fundamental II e Médio. 2016. Disponível em: <https://repositorio.unesp.br/handle/11449/155413>. Acesso em: 5 abr. 2018.

Recebido em agosto de 2018. Aprovado em outubro de 2018. Publicado em dezembro de 2018. 